\title{
A RELAÇÃO ENTRE A IMAGEM DO VAREJO DE VESTUÁRIO E A LEALDADE DOS CONSUMIDORES DA GERAÇÃO Y
}

\author{
THE RELATION BETWEEN CLOTHING RETAIL IMAGE \\ AND THE LOYALTY OF THE GENERATION Y'S CONSUMERS
}

\section{LA RELACIÓN ENTRE LA IMAGEN DEL VESTUARIO DEL VAREJO Y LA LEALTAD DE LOS CONSUMIDORES DE LA GENERACIÓN Y}

\author{
Deonir de Toni \\ Professor na Graduação e Pós-Graduação Lato e Stricto \\ Sensu da Universidade de Caxias do Sul (UCS), Brasil / \\ Pós-Doutor em Administração pela Universidade de São \\ Paulo (USP), Brasil \\ deonirdt@terra.com.br
}

Virginia Dal Ponte

Mestre em Administração pela Universidade de Caxias do Sul (UCS), Brasil

virginia.dalponte@gmail.com

\author{
Ana Paula Graciola \\ Mestre em Administração pela Universidade de Caxias \\ do Sul, Brasil \\ anagraciola@gmail.com
}

\author{
Gabriel Sperandio Milan \\ Professor e pesquisador do Programa de Pós-Graduação \\ em Administração (PPGA) na Universidade de Caxias \\ do Sul (UCS), Brasil / Pós-Doutor em Administração na \\ área de Marketing pela Universidade Federal do Rio \\ Grande do Sul (UFRGS), Brasil \\ gabmilan@terra.com.br
}

Contextus

ISSNe 2178-9258

Organização: Comitê Científico Interinstitucional Editor Científico: Diego de Queiroz Machado Avaliação: double blind review pelo SEER/OJS Edição de texto e de layout: Carlos Daniel Andrade Recebido em 25/09/2017 Aceito em 06/03/2018 $2^{\mathrm{a}}$ versão aceita em $22 / 03 / 2018$

\section{RESUMO}

A geração Y é representada por adolescentes e jovens adultos nascidos entre 1980 e 2000. É uma geração de consumidores com grande poder econômico, com capacidade estimada de compra anual de 200 bilhões de dólares. Nesse cenário, o objetivo desta pesquisa é identificar a relação entre as dimensões da imagem de varejo de vestuário e a lealdade dos consumidores da geração Y. O framework proposto baseou-se na revisão bibliográfica sobre imagem de loja e lealdade. A pesquisa é do tipo survey, com 394 consumidores da geração Y. Os resultados apontam que a imagem de loja tem impacto sobre a dimensão da lealdade. Dentre as dimensões que mais explicam a imagem de loja, destacaram-se as de serviços, mix de produtos (mercadorias) e atmosfera da loja.

Palavras-chave: Imagem de Loja. Lealdade. Varejo. Modelo conceitual da imagem de loja. Geração Y.

\begin{abstract}
The generation $\mathrm{Y}$ is represented by adolescents and young adults that were born between 1980 and 2000 . It is the wallet power generation, with estimated annual spending capacity of 200 billion dollars. In this scenario, the principal aim of this research is to identify the relationship between dimensions of the clothing retail image and the loyalty of the generation Y customers. The proposed framework was based on the literature review of store image and loyalty. The survey was applied to 394 generation Y's consumers. The results indicated that the store
\end{abstract}


image has an impact on the loyalty dimension. Among the dimensions of the image store, the following ones stood out: services, merchandise mix and store atmosphere.

Keywords: Store Image. Loyalty. Retailing. Conceptual model of store image. Generation Y.

\section{RESUMEN}

La Generación Y es representada por adolescentes y jóvenes adultos nacidos entre 1980 y 2000. Es una generación de consumidores con gran poder económico, con una capacidad estimada de compra anual de 200 mil millones de dólares. En este escenario, el objetivo de esta investigación es identificar la relación entre las dimensiones de la imagen del vestuario y la lealtad de los consumidores de la generación Y. El marco propuesto fue basado en la revisión de la literatura en relación a la imagen de la tienda y a la lealtad. La investigación es del tipo survey, aplicada a 394 consumidores de la generación Y. Los resultados apuntan que la imagen de la tienda tiene impacto en la lealtad. Entre las dimensiones que más explican la imagen de tienda, se destacaron las de servicio, mezcla de productos (mercancías) y la atmósfera de la tienda.

Palabras Clave: Imagen de la tienda. Lealtad. Varejo. Modelo conceptual de la imagen de la tienda. Generación Y.

\section{INTRODUÇÃO}

Os mercados varejistas se transformam em resposta às mudanças tecnológicas, econômicas e sociais existentes para suprir as necessidades dos consumidores. Para Borges, Babin e Spielmann (2013), na atual dinâmica dos ambientes de varejo, os consumidores buscam por ofertas de mercadorias e ambientes diferenciados (BITNER, 1992; BORGES; BABIN; SPIELMANN, 2013).

Desse modo, os consumidores estão mais informados e sofisticados, com necessidades específicas de consumo que devem ser compreendidas pelos varejistas (NORTH, DE VOS; KOTZE, 2003).

Nesse panorama, a importância do setor de vestuários para a economia brasileira é percebida através dos valores de vendas de $\mathrm{R} \$ 14,5$ bilhões em maio de 2016. Nesse mesmo período, o Brasil exportou US\$10,8 milhões em vestuários, tendo como principais clientes o Paraguai
$(22,2 \%)$, os Estados Unidos $(13,9 \%)$ e a Bolívia (12,6\%) (IEMI, 2016). Em nível mundial, o Brasil ocupa a quarta posição entre os maiores produtores mundiais de artigos de vestuário (ABIT, 2009; IEMI, 2014). Também se constatou que o volume de vendas de vestuário no varejo avançou 13,8\% em novembro de 2017 (IEMI, 2018).

A imagem de varejo gera diferenciação para as empresas, projetando-as através do mix de comunicação e modificando a visão dos consumidores (LEWIS; HAWKSLEY, 1990; MARKWICK; FILL, 1997). A imagem de loja está relacionada aos comportamentos de consumo, como a lealdade à loja, decisões de compras e percepção de valor (ASSAEL, 1992). Markwick e Fill (1997) destacam que os estudos sobre a imagem são projetados para expor os atributos-chave da empresa, que podem alimentar as informações necessárias para a formulação das 
estratégias. Esse tipo de informação permite o alinhamento da empresa com o mercado e com o público-alvo, definindo as estratégias para comunicar uma imagem específica de loja (MARKWICK; FILL, 1997).

Du Preez et al. (2006a, b, c) trazem contribuições sobre a configuração de imagem de varejo, com enfoque sobre o vestuário, ao desenvolverem um modelo teórico contextualizado na África do Sul. Tal modelo comtempla as dimensões de imagem e suas contribuições para a formação da imagem de loja na percepção do consumidor.

James, Durand e Dreves (1976) apontam estudos sobre a imagem em segmentos específicos de mercado e incluem um público-alvo específico. Para este estudo, foram escolhidos os consumidores da geração Y. São os indivíduos nascidos no final dos anos 1980 e início de 2000. Dessa geração fazem parte oitenta e dois milhões de pessoas, com um poder aquisitivo de 200 bilhões de dólares anualmente (TAPSCOTT, 1999; WATERS, 2006; DJAMASBI; SIEGEL; TULLIS, 2010).

Essa geração consome mais que as anteriores, interessa-se por bens materiais, tem um perfil de consumo diferenciado e usa tecnologias como fonte de informação. O processo de decisão de compra inclui experiências, anúncios, propagandas, indicações e avaliações de amigos e a Internet como fonte de informação (TAPSCOTT; WILLIAMS, 2007). Além do mais, estudos futuros devem concentrar-se em características específicas dos consumidores, como idade e classe social (DO VALE; MATOS; CAIADO, 2016). Poucas pesquisas têm direcionado seus estudos para a geração $\mathrm{Y}$ (DJAMASBI; SIEGEL; TULLIS，2010), mas conhecê-la é fundamental para que o varejo de vestuário melhore seu posicionamento no mercado competitivo.

Diante do exposto, o objetivo geral deste estudo é verificar a relação entre a imagem de varejo e a lealdade à loja dos consumidores da geração $\mathrm{Y}$, no sul do Brasil. E foram estabelecidos os seguintes objetivos específicos: (i) verificar os principais construtos que formam a imagem de varejo de vestuário; (ii) verificar o impacto da imagem de loja de vestuário na lealdade à loja por consumidores da geração $\mathrm{Y}$ e; (iii) verificar a moderação das variáveis sexo, frequência de compra e renda sobre as dimensões que configuram a imagem de loja e a lealdade à loja. A seguir, apresenta-se a literatura sobre as dimensões que compõem o modelo em estudo. 


\section{REFERENCIAL TEÓRICO}

\subsection{A imagem de loja}

A imagem é uma estrutura subjetiva de conhecimentos, resultante de experiências passadas do sujeito em contato com o objeto da imagem (BOULDING, 1968). Na perspectiva mercadológica, foi proposta a existência de três tipos de imagens: a imagem de marca ou produto, a imagem da corporação e a imagem da loja (STERN; ZINKHAN; JAJU, 2001). O presente trabalho tem como foco a imagem de loja.

O conceito de imagem de loja foi abordado inicialmente por Martineau (1958, p. 55) ao descrever a imagem de loja como a "personalidade da loja de varejo". Porter e Claycomb (1997) afirmam que a imagem de loja está associada aos pensamentos dos consumidores, formados ao longo dos anos, e ao sentimento que eles, por sua vez, associam às lojas e que impacta diretamente o seu comportamento de compra. Para Kim e Jin (2001), a satisfação do consumidor resulta de sua experiência emocional durante a fase de compra e da avaliação das dimensões da loja. Para Beristain e Zorrilla (2011), a imagem de loja é concebida como um conjunto de associações de marca de natureza comercial, social e estratégica (BERISTAIN; ZORRILLA, 2011).

Assael (1992) afirma que a imagem de loja contribui para a mensuração e identificação das forças e fraquezas do varejo, através de abordagens corretas e eficientes, de modo a garantir influência positiva sobre os consumidores (ASSAEL, 1992). A compreensão de quais atributos compõem a imagem de varejo é fundamental para identificar a configuração de imagem na mente do consumidor (BOULDING, 1968; MAY, 1974). Para Baker, Parasuraman, Grewal e Voss (2002), as dimensões da imagem de varejo podem ser uma ferramenta para avaliar os valores de consumo e os critérios de escolha de loja, utilizada para comunicar e interagir com os clientes, gerar satisfação e lealdade dos consumidores

(BAKER;

PARASURAMAN; GREWAL; VOSS, 2002).

Para um varejista de vestuário, a imagem de loja é uma maneira de se diferenciar dos demais e ser único para seus clientes. Estes utilizam a imagem de loja como critério de avaliação no processo de tomada de decisão em relação a escolha da loja, num ambiente altamente competitivo e saturado. Logo, a posição que o varejista ocupa na mente do consumidor é vital para se diferenciar da 
concorrência (VARLEY, 2005). Nesse contexto, os varejistas podem decidir qual imagem suas lojas irão projetar para o seu mercado alvo (OSMAN, 1993).

Thang e Tan (2003) argumentam que o consumidor registra suas preferências através da percepção das dimensões da imagem da loja. Tais preferências influenciam as decisões de compra. Logo, a imagem de loja tem a capacidade de atrair clientes. No entanto, as expectativas do consumidor só serão atendidas se ele não perceber nenhuma lacuna. Portanto, o conhecimento das dimensões que constituem a imagem de loja conduz à diferenciação do varejista, em relação as outras lojas disponíveis ao consumidor (VISSER et al., 2006).

Neste trabalho, o modelo de imagem de loja (MIL) utilizado é aquele apresentado por Janse Van Noordwyk (2008), com base no estudo piloto desenvolvido por Du Preez, Janse Van Noordwyk e Visser (2006a, b, c), que tratam de oito dimensões: (i) atmosfera (interior e atmosfera da loja); (ii) conveniência (transporte, localização, estacionamento, facilidade de compra, horário da loja); (iii) instalações (aparência da loja, conveniência de instalações, iluminação); (iv) institucional (clientela, reputação da loja); (v) mercadoria (variedade, estilo, preço, qualidade); (vi) promoção (publicidade, exposições, incentivos de compras); (vii) pessoal de vendas (interação, aparência) e; (viii) serviços (pós-venda, serviços oferecidos no interior da loja). A seguir serão detalhadas cada uma das dimensões.

A atmosfera de loja refere-se especificamente ao design e fatores ambientais que influenciam na preferência do consumidor (BAKER et al., 2002; THANG; TAN, 2003). Os consumidores utilizam a atmosfera para fazer inferência sobre a qualidade, que também gera influência sobre o comportamento (BITNER, 1992; DARDEN; BADIN, 1994; BAKER et al. 1994; BORGES; BABIN; SPIELMANN, 2013). Newman e Patel (2004) relataram que a atmosfera é um dos fatores cruciais e determinantes da escolha da loja. Os aspectos estéticos de uma loja podem melhorar a avaliação da qualidade dos produtos por parte dos clientes (RICHARDSON et al., 1996). O design interno é percebido com menos relevância pelos varejistas, em comparação com seus clientes, porém é um aspecto controlável que pode contribuir para a satisfação do cliente através de expectativas gratificantes

(TERBLANCHÉ; BOSHOFF, 2006). Portanto, os consumidores com necessidades variadas apresentam comportamentos diferentes frente aos 
estímulos causados pela atmosfera de loja (WANG; CHANG; WYSONG, 2012).

Chang e Tu (2005) constataram que a conveniência está relacionada à satisfação e lealdade do cliente com a imagem da loja. Ou seja, a distância da loja influencia na intenção de permanecer fiel. Hyllegard et al. (2005) constataram que a facilidade de acesso e o tempo de viagem até a loja é menos importante para os consumidores com mais idade, por terem mais tempo. Para os jovens, por sua vez, o tempo é mais relevante, pois percebem a facilidade de acesso, o tempo de viagem e o horário de atendimento estendido como fatores para a decisão de compra (CHANG; TU, 2005).

As instalações se referem à infraestrutura, que pode proporcionar mais conforto para o consumidor na hora da compra. Os consumidores tendem a ver uma loja com boas instalações como favorável às suas opções de compras, o que diferencia a loja de seus concorrentes (THANG; TAN, 2003). As instalações que contribuem para essa diferenciação facilitam o processo de compra, ou seja, aquelas caracterizadas pela disponibilidade dos vestiários, pelo layout e pelo pagamento/check-out rápidos, conforme apontam Newman e Patel (2004). Estes concluem que as percepções e comportamentos dos consumidores podem ser controlados em função de pequenas alterações na imagem de loja, especialmente nas suas entradas, filas e caixas. Para Kent (2003), a imagem da loja é melhorada por elementos funcionais: o acesso aos produtos, o espaço físico com corredores abertos e a maximização do espaço de vendas (KENT, 2003).

A reputação de uma loja pode afetar o comportamento do consumidor, em decorrência do envolvimento com a identidade da loja, reconhecendo nela características de seu estilo de vida (HUDDLESTON et al., 1990). Erdem, Oumlil e Tuncalp (1999) estudaram a relação entre os valores de consumo e a importância dos atributos na imagem de loja, concluindo que os consumidores ligados a uma vida confortável e de reconhecimento social atribuem grande importância ao status da loja, que inclui a clientela e a reputação. De acordo com Newman e Patel (2004), a identidade adiciona um aspecto simbólico ao ato de compra: a imagem de loja incentiva a lealdade de clientes, que formam, posteriormente, um grupo a influenciar o comportamento coletivo (NEWMAN; PATEL, 2004).

A dimensão mercadoria inclui sortimento, marca, estilo, preço e qualidade das mercadorias. Para CollinsDodd e Lindley (2003), assim como para 
Thang e Tan (2002), a mercadoria e a marca são os fatores mais importantes para a preferência do consumidor por determinado varejista (COLLINS-DODD; LINDLEY, 2003; THANG; TAN, 2002). A imagem de loja pode ser fortalecida pelo efeito positivo do mix de produtos (mercadoria), pois o cliente pode, em uma única visita, sentir-se satisfeito ou não e instantaneamente confirmar sua percepção da loja (NEWMAN; PATEL, 2004). Portanto, a percepção do sortimento de mercadorias é a chave principal que determina as preferências dos consumidores durante as compras (SIMONSON, 2005; $\quad$ YOON; SIMONSON, 2008; PIRIS; GUIBERT, 2015).

A promoção é uma importante ferramenta no processo de aproximação da loja com seus consumidores. O objetivo da promoção é dar reconhecimento à marca (RATNATUNGA; EWING， 2005). Os displays são vistos como incentivadores de consumo, agem para conscientizar os clientes sobre a possível compra e o uso de determinada mercadoria. A vitrine, por seu turno, contribui para a entrada do cliente na loja (SEN; BLOCK; CHANDRAN, 2002). Du Frene et al. (2005) indicam que a publicidade centrada no consumidor pode mudar suas atitudes em relação à loja.
$O$ pessoal de vendas desempenha papel fundamental na criação de interações sociais e melhora as avaliações da imagem de loja. A construção de relações interpessoais com os clientes gera a lealdade à loja (HU; JASPER, 2006). A percepção dos clientes quanto ao serviço, que inclui as interações com o pessoal de vendas, melhora sua percepção da mercadoria e afetam significativamente a escolha da loja (TELLER; KOTZAB; GRANT, 2006).

Segundo Thang e Tan (2003), os clientes têm percepções mais favoráveis e voltam a frequentar as lojas que oferecem serviços melhores. E, para Brady et al. (2002), a qualidade nos serviços é um dos fatores que mais impactam nas decisões de compra dos consumidores. Os serviços diferenciados conduzem a comportamentos positivos dos consumidores e aumentam a frequência com que eles vão às lojas (CARRILLAT et al., 2009; CRONIN; TAYLOR, 1992; FORNELL, 1992; SZYMANSKI; HENARD, 2001; ZEITHAML et al., 1996). Nesse cenário, as dimensões que formam a imagem de loja são as seguintes: (i) atmosfera de loja; (ii) conveniência; (iii) instalações; (iv) institucional; (v) mercadoria; promoção; (vii) pessoal de vendas e; (viii) serviços. 


\subsection{Lealdade à loja}

A lealdade do consumidor à loja é vista como manifestação pós-compra (ESPARTEL, 2004). Lealdade refere-se ao ato de comprar novamente na mesma loja, de forma não aleatória (OSMAN, 1993). Expressa-se ao longo do tempo, por uma tomada de decisão a respeito de uma loja, em relação a um conjunto de outras lojas, de forma avaliativa, que resulta em compromisso. Quando a pessoa se torna comprometida com a loja ela torna-se fiel, ou seja, compromisso é condição necessária para que a fidelidade à loja aconteça (BLOEMER; DE RUYTER, 1998). No contexto comportamental, o termo lealdade é utilizado indefinidamente em relação as definições referentes à repetição de compra, probabilidade de compra, proporção de compra, probabilidade de recompra, frequência de compra, sequência de compra, preferência, comprometimento, retenção ou fidelidade. Também se refere a contextos de lealdade à marca, ao serviço, à loja ou ao vendedor (ESPARTEL, 2005; BENNETT; RUNDLE-THIELE， 2002; KUMAR; SHAH, 2004).

Para Oliver (1999), lealdade compreende um profundo envolvimento em recomprar um produto/serviço no futuro. Espartel (2005) complementa que a lealdade implica num comprometimento forte do cliente com a marca. Ao passo que, mesmo que exista outra marca, o cliente tende a comprar repetidamente a sua marca preferida. Yoo, Donthu e Lee (2000) entendem que a lealdade à marca existe quando os consumidores realizam uma determinada escolha de compra rotineiramente e resistem à escolha de outra marca. A lealdade pode ser considerada, também, como a intenção do consumidor de comprar uma determinada marca, como sua primeira opção de escolha (YOO; DONTHU, 2001).

Antecedentes da lealdade têm recebido atenção pelos pesquisadores (ORTH; GREEN, 2009). Portanto, um dos principais antecedentes da lealdade é a imagem de loja (ANDERSON; WEITZ, 1989; DE WULF; ODEKERKENSCHRÖDER; LACOBUCCI, 2001; ORTH; GREEN, 2009). Bloemer e De Ruyter (1998) afirmam que a percepção de imagem de loja está diretamente relacionada à lealdade à loja. Pois, a identidade da loja apresentada e comunicada através de sua imagem diferencia da loja, otimiza as respostas dos consumidores em relação suas atitudes e orientações para compras (KIM; JIN, 2001). No estudo desenvolvido por Orth e Green (2009), os autores apontam que diferentes elementos da imagem de loja 
influenciam diretamente na lealdade dos consumidores (ORTH; GREEN, 2009).

Além do mais, evidências tanto em pesquisas teóricas e estudos empíricos indicaram que a imagem de loja é positivamente relacionada à lealdade (ORTH; GREEN, 2009; BLOEMER; DE RUYTER, 1998; OSMAN, 1993).

Portanto, se o consumidor presenciar uma boa experiência na loja, uma imagem favorável é criada, ele irá desenvolver um certo grau de lealdade, que é proporcionada pela imagem favorável da loja (ORTH; GREEN, 2009; SIRGY; SAMLI, 1985). Dimensões da imagem de loja impactam na lealdade, como é o caso do efeito direto do preço/valor e serviços sobre a lealdade (ORTH; GREEN, 2009; SIROHI et al., 1998). A seguir a primeira hipótese é apresentada:

\section{$\mathrm{H}_{1}$ : A imagem de loja tem um} impacto direto e positivo na lealdade.

A partir da revisão da literatura, a Figura 1 apresenta o Modelo Teórico que compreende a união dos estudos realizados por Preez, Visser e Van Noordwyk (2006) através da abordagem sobre a multidimensionalidade da imagem de loja e a lealdade de De Toni et al. (2013). Assim, a principal contribuição deste estudo, reside na verificação do impacto das dimensões da imagem de loja, em segunda ordem, sobre a lealdade dos consumidores.

Figura 1 - Modelo teórico da configuração da imagem de varejo sobre a lealdade

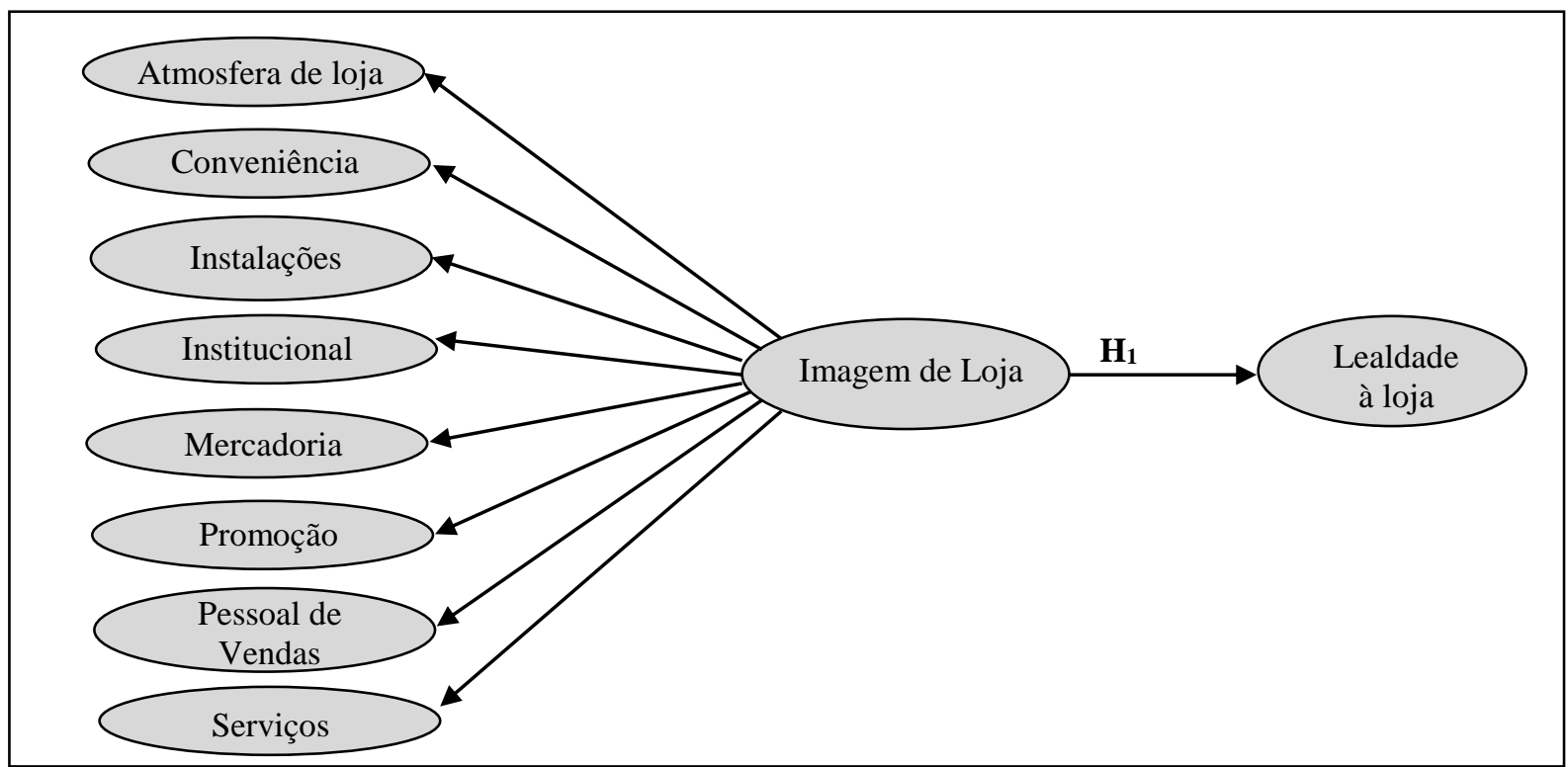

Fonte: Adaptado de Preez, Visser e Van Noordwyk (2006) e De Toni et al. (2013). 


\section{MÉTODO DE PESQUISA}

Para verificar as relações do modelo sugerido, realizou-se uma pesquisa de natureza quantitativo-descritiva (HAIR Jr. et al., 2010; MALHOTRA; BIRKS; WILLS, 2012), com uma survey de corte transversal (FOWLER Jr., 2009; HAIR Jr. et al., 2010; REMLER; VAN RYZIN, 2011). Os dados foram coletados por meio de um questionário estruturado, validado mediante pré-teste (33 questionários) e aplicado a uma amostra da população na Serra Gaúcha/RS (HAIR Jr. et al., 2010). Como técnica para analisar os dados, foi utilizada a modelagem de equações estruturais (MEE), considerada uma extensão de diversas técnicas e procedimentos multivariados (KLINE, 2011). Dentro da MEE, foram utilizadas a Análise Fatorial Confirmatória (AFC) e a Análise de Caminhos (Path Analysis). O método de estimação utilizado foi o de máxima verossimilhança (Maximum Likelihood - ML), indicado para amostras superiores a 200 casos (HAIR Jr. et al., 2010).

$\mathrm{Na}$ elaboração do instrumento de coleta de dados, para operacionalizar a escala, definiu-se a utilização de uma escala do tipo Likert de cinco pontos. As respostas possíveis para os construtos da imagem de loja variaram desde " 1 - Sem importância" até "5 - Muito importante". E, para a dimensão da lealdade, os extremos foram "1 - improvável" e "5 Muito provável" (BEARDEN et al., 2011; NETEMEYER et al., 2003). Cabe comentar que as escalas utilizadas foram operacionalizadas a partir de estudos anteriores, com a utilização de escalas validadas, conforme mostram as Tabelas 1 e 2. Uma vez elaborado e estruturado o questionário de pesquisa, procedeu-se à validação de conteúdo, também conhecida como validade de face (KINNEAR; TAYLOR, 1996), pela qual o instrumento de coleta de dados foi submetido a três experts da área.

O questionário foi estruturado com dimensões oriundas dos estudos de Du Preez et al. (2006a, b, c) sobre a imagem de loja e De Toni et al. (2013) sobre a dimensão lealdade. A imagem de loja é composta por: (i) atmosfera com 06 variáveis; (ii) conveniência com 07 variáveis; (iii) instalações com 07 variáveis; (iv) institucional com 06 variáveis; (v) mercadoria com 08 variáveis; (vi) promoção com 08 variáveis; (vii) vendedores/pessoal de vendas com 05 variáveis e; (viii) serviços com 08 variáveis (DU PREEZ et al. (2006a, b, c). E por fim, a variável dependente, a lealdade foi composta por 10 variáveis $(\mathrm{DE}$ TONI et al., 2013). Na sequência serão 
apresentadas as análises dos resultados.

\section{ANÁLISE DOS RESULTADOS}

A população considerada para esta pesquisa é representa pela geração Y (pessoas nascidas nos anos de 1980 a 2000) (TAPSCOTT, 1999). A geração Y estuda em universidades e representa um grupo significante e/ou potencial de consumidores (TAYLOR; CONSENZA, 2002; VALENTINE; POWERS, 2013). Portanto, para compreender tal grupo foram selecionados por conveniência alunos de uma universidade da Serra Gaúcha/RS que fossem consumidores em lojas varejistas de vestuário. Optou-se por utilizar os estudantes universitários em virtude de a amostra ser mais homogênea e, ao mesmo tempo, de seus membros pertencerem ao público-alvo dos consumidores em estudo (VISSER; DU PREEZ; JANSE VAN NOORDWYK, 2006). A coleta de dados foi realizada nos meses de maio e junho de 2014, com o método de autopreenchimento (FOWLER Jr., 2009; FINK, 2013). A técnica de amostragem não probabilística foi escolhida para o estudo por conveniência (MALHOTRA; BIRKS; WILLS, 2012).

Obteve-se uma amostra final de 394 respondentes, dos quais 209 (53\%) eram do sexo masculino, $182(46 \%)$ do sexo feminino, e 3 (1\%) missing values. Do mesmo total, 108 (27\%) apresentavam idade entre 16 e 20 anos, 115 (29\%) entre 21 e 23 anos, 76 (19\%) de 24 a 27 anos, 36 (9\%) de 28 a 30 anos, 39 (10\%) de 31 a 35 anos, e 20 (5\%) acima de 36 anos. Com relação à renda mensal bruta, 134 (34\%) dos indivíduos recebiam de $\mathrm{R} \$ 622,00$ a 1.448,00, 98 (25\%) de R\$ 1.448,00 a 2.172,00, $65(16 \%)$ entre $R \$ 2.172,00$ e $3.620,00$, e $42(11 \%)$ de $\mathrm{R} \$ 3.620,00$ a 7.240,00. Dos mesmos 394 respondentes, $118(30 \%)$ compram roupas mensalmente, e $121(31 \%)$ gastam mensalmente entre $R \$$ 100,00 e 199,00 em roupas.

\subsection{Análise dos dados e validade do modelo de mensuração}

Dos 412 questionários, dois questionários foram eliminados em decorrência da falta de consistência, com mais de $10 \%$ de não resposta (missing data). Após o diagnóstico dos dados perdidos, foi constatado que estes são perdidos ao acaso (Missing at Running MAR) $\left(\chi^{2}=5001,256\right.$, Graus de Liberdade $=4479, p=0,000)$ (HAIR JR. et al., 2010). Através das observações atípicas, na verificação dos outliers, com base em análises univariadas ( $Z$ scores) dezesseis questionários foram excluídos, e através de análises multivariadas, teste da distância de 
Mahalanobis (D2), nenhum caso foi excluído. Após estes testes, 394 casos são considerados válidos (HAIR Jr. et al., 2010; KLINE, 2011).

Também foram realizados os testes de normalidade, linearidade e multicolinearidade. No teste de normalidade, os valores estão de acordo com o permitido, com valores para a curtose (kurtosis) (-1,032 e 3,272) e assimetria (skewness) (-1,734 e 0,306) adequados. No teste da homoscedasticidade apresentou valor significante $(p<0,000)$ no teste de $\mathrm{M}$ de Box, no teste de Levene, apenas as variáveis MER34; PRO40 e PRO42 apresentaram padrões de heteroscedasticidade em mais de uma variável não métrica com níveis de significância menor de 0,05. Deste modo, como as variáveis são consideradas relevantes para o estudo, optou-se em mantê-las nas análises das equações estruturais.

Quanto a linearidade, realizado pelo teste do coeficiente de Correlação de Pearson, que varia de -1 a +1 , foi constatado que os valores estão dentro do intervalo permitido, com valores para os coeficientes positivos e menores que 0,967 e com $\mathrm{p}<0,000$. E, por fim, a multicolinearidade, nos testes de tolerância $(0,454$ e 0,899$)$ e fator de inflação de variância (VIF - Variance Inflation Factor) (1,11 e 2,20). Portanto, todas as variáveis apresentaram multicolinearidade aceitável (HAIR Jr. et al., 2010). As Tabelas 1 e 2 apresentam a análise fatorial dos construtos em estudo.

Tabela 1 - Análise fatorial confirmatória dos indicadores das variáveis latentes do construto Imagem de Loja

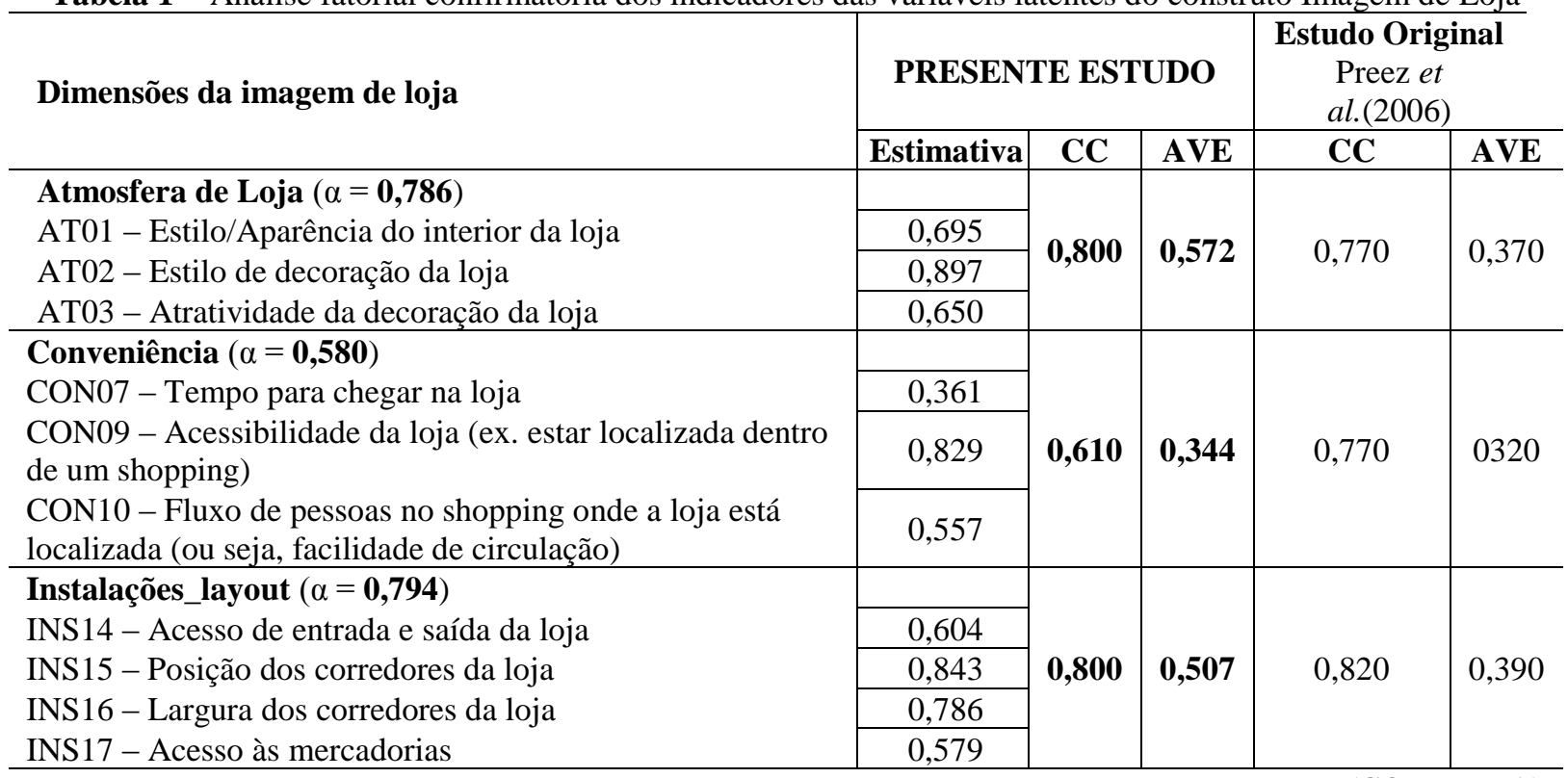


(CONTINUAÇÃO)

\begin{tabular}{|c|c|c|c|c|c|}
\hline \multirow{4}{*}{$\begin{array}{l}\text { Institucional }(\alpha=\mathbf{0 , 6 6 5}) \\
\text { INT24 - Identificação dos amigos } \\
\text { INT25 - Relação entre a imagem da loja e a autoimagem } \\
\text { INT26 - Construção de relacionamento com os clientes }\end{array}$} & & \multirow{4}{*}{0,670} & \multirow{4}{*}{0,405} & \multirow{4}{*}{0,760} & \multirow{4}{*}{0,350} \\
\hline & 0,611 & & & & \\
\hline & 0,735 & & & & \\
\hline & 0,550 & & & & \\
\hline \multirow{5}{*}{$\begin{array}{l}\text { Mercadoria (mix produtos) }(\alpha=\mathbf{0 , 8 0 9}) \\
\text { MER28 - Disponibilidade de mercadorias importadas } \\
\text { MER29 - Disponibilidade de mercadorias originais (ex. } \\
\text { mercadorias oferecidas somente pela loja) } \\
\text { MER30 - Disponibilidade de mercadorias exclusivas (peças } \\
\text { limitadas } \\
\text { MER31 - Disponibilidade de mercadorias de marca/grife }\end{array}$} & & \multirow{5}{*}{0,811} & \multirow{5}{*}{0,521} & \multirow{5}{*}{0,840} & \multirow{5}{*}{0,400} \\
\hline & 0,592 & & & & \\
\hline & 0,701 & & & & \\
\hline & 0,794 & & & & \\
\hline & 0,781 & & & & \\
\hline \multirow{4}{*}{$\begin{array}{l}\text { Promoção }(\alpha=\mathbf{0 , 7 0 4}) \\
\text { PRO40 - Venda de produtos de baixo preço (promoção) } \\
\text { PRO41 - Anúncio oportuno de vendas } \\
\text { PRO42 - Disponibilidade de ofertas especiais (ex. compre } \\
\text { um, ganhe outro) }\end{array}$} & & \multirow{4}{*}{0,710} & \multirow{4}{*}{0,454} & \multirow{4}{*}{0,830} & \multirow{4}{*}{0,380} \\
\hline & 0,699 & & & & \\
\hline & 0,547 & & & & \\
\hline & 0,758 & & & & \\
\hline \multirow{5}{*}{$\begin{array}{l}\text { Vendedores }(\alpha=\mathbf{0 , 7 9 5}) \\
\text { VEN43 - Vendedores com estilo moderno/arrojado } \\
\text { VEN45 - Semelhança entre pessoal de vendas e você (ex. } \\
\text { tamanho de roupas) } \\
\text { VEN46 - Similaridade de idade entre os vendedores e você } \\
\text { VEN47 - Semelhança de gostos/estilo entre os vendedores e } \\
\text { você }\end{array}$} & & \multirow{5}{*}{$\mathbf{0 , 8 0 0}$} & \multirow{5}{*}{0,510} & \multirow{5}{*}{0,840} & \multirow{5}{*}{0,520} \\
\hline & 0,472 & & & & \\
\hline & 0,696 & & & & \\
\hline & 0,848 & & & & \\
\hline & 0,784 & & & & \\
\hline \multirow{5}{*}{$\begin{array}{l}\text { Serviços }(\alpha=\mathbf{0 , 7 9 6}) \\
\text { SER48 - Especialização do pessoal de vendas } \\
\text { SER49 - Cortesia do pessoal de vendas } \\
\text { SER50 - Número de vendedores } \\
\text { SER51 - Disponibilidade do pessoal de vendas }\end{array}$} & & \multirow{5}{*}{$\mathbf{0 , 8 0 0}$} & \multirow{5}{*}{$\mathbf{0 , 5 0 7}$} & \multirow{5}{*}{0,800} & \multirow{5}{*}{0,340} \\
\hline & 0,680 & & & & \\
\hline & 0,521 & & & & \\
\hline & 0,760 & & & & \\
\hline & 0,842 & & & & \\
\hline
\end{tabular}

Fonte: Dados provenientes da pesquisa.

A seguir é apresentada a Tabela 2, que representa a dimensão da lealdade.

Tabela 2 - Análise fatorial confirmatória dos indicadores das variáveis latentes do construto Lealdade

\begin{tabular}{|c|c|c|c|}
\hline Lealdade $(\alpha=.904)$ & Estimativa & $\mathbf{C C}$ & AVE \\
\hline LEA64 - Frequentarei estas lojas novamente? & 0,657 & \multirow{10}{*}{0,917} & \multirow{10}{*}{$\mathbf{0 , 5 2 7}$} \\
\hline LEA65 - Comprarei mais produtos nestas lojas? & 0,682 & & \\
\hline LEA66 - Direi coisas positivas sobre estas lojas para outras pessoas? & 0,743 & & \\
\hline $\begin{array}{l}\text { LEA67 - Considerarei estas lojas como uma das primeiras opções de } \\
\text { compra em relação a outras da mesma categoria? }\end{array}$ & 0,685 & & \\
\hline \multirow{4}{*}{$\begin{array}{l}\text { LEA68 - Recomendarei estas lojas a amigos, vizinhos e parentes? } \\
\text { LEA69 - Encorajarei amigos e parentes a comprar nestas lojas? } \\
\text { LEA70 - Estas lojas são opções de boa compra? } \\
\text { LEA71 - Eu sou propenso(a) a fazer comentários positivos sobre estas } \\
\text { lojas para outras pessoas? }\end{array}$} & 0,749 & & \\
\hline & 0,692 & & \\
\hline & 0,781 & & \\
\hline & 0,741 & & \\
\hline LEA72 - Eu consideraria estas lojas para compra? & 0,695 & & \\
\hline LEA73 - Eu provavelmente comprarei nestas lojas no futuro? & 0,693 & & \\
\hline
\end{tabular}

Fonte: Dados provenientes da pesquisa.

Nota: CC - Confiabilidade Composta; AVE - Variância Extraída

Em cada construto (Tabelas 1 e 2)

foi verificada a consistência interna
(Cronbach's alpha), a estimativa

(estimate), a confiabilidade composta (CC) 
e a variância extraída (AVE), como sugerem Fornell e Larcker (1981). Foram considerados valores aceitáveis para os alfas com coeficientes maiores que 0.60 (MALHOTRA; BIRKS; WILLS， 2012; HAIR Jr. et al., 2010). As dimensão Institucional e Conveniência foram retiradas do modelo proposto, por dois motivos principais: o primeiro, por apresentarem baixa confiabilidade composta (abaixo de 0,70) e baixa variância extraída (abaixo de 0,50) (HAIR et al., 2010) e; segundo, em função que no modelo original proposto por $\mathrm{Du}$ Preez, Visser e Janse Van Noordwyk (2006a, b, c) também apresentaram estas duas dimensões uma variância extraída baixa (0,32 para conveniência e 0,35 para institucional). A Tabela 3 apresenta a validação do modelo estrutural para cada construto em estudo.

Tabela 3 - Análise da qualidade dos ajustes (GOF) para cada construto em estudo

\begin{tabular}{|c|c|c|c|c|c|c|c|}
\hline \multirow[b]{2}{*}{ Índices } & \multicolumn{7}{|c|}{ Construtos Analisados } \\
\hline & 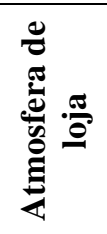 & 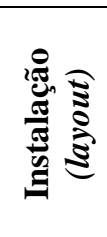 & 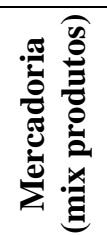 & 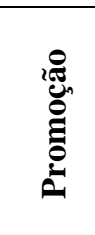 & 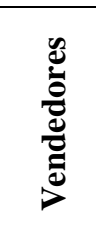 & : & 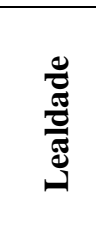 \\
\hline GFI $(>0,9)$ & 0,988 & 0,994 & 0,972 & 0,993 & 0,981 & 0,954 & 0,818 \\
\hline AGFI $(>0,9)$ & 0,929 & 0,972 & 0,858 & 0,960 & 0,903 & 0,770 & 0,714 \\
\hline $\operatorname{RMSEA}(0,05$ a 0,08$)$ & 0,125 & 0,054 & 0,174 & 0,087 & 0,138 & 0,212 & 0,164 \\
\hline $\mathrm{NFI}(>0,9)$ & 0,980 & 0,991 & 0,952 & 0,982 & 0,967 & 0,929 & 0,830 \\
\hline TLI $(>0,9)$ & 0,949 & 0,986 & 0,865 & 0,959 & 0,913 & 0,797 & 0,797 \\
\hline CFI $(>0,9)$ & 0,983 & 0,995 & 0,955 & 0,986 & 0,971 & 0,932 & 0,842 \\
\hline
\end{tabular}

Fonte: Dados provenientes da pesquisa.

$\mathrm{Na}$ Tabela 3, para validação do modelo estrutural foi utilizado com base na MEE o método de Máxima Verossimilhança (ML - Maximum Likelihood) para ajustar os construtos e identificar a qualidade destes ajustes (GOF - Goodnessof Fit) que engloba o quiquadrado, GFI e RMSEA, AGFI, TLI, NFI e CFI e o qui-quadrado por Graus de liberdade, tanto para cada dimensão avaliada como para o modelo geral proposto, onde foi possível identificar que, de modo geral, a qualidade do ajustamento pode ser considerada satisfatória (HAIR Jr. et al., 2010; BAGOZZI; YI, 2012). Neste estudo, optou-se pelo método de Fornell e Larcker (1981) para verificar a validade discriminante que é alcançada quando a variância extraída de cada construto é maior que as variâncias compartilhadas (correlações ao quadrado) com outros construtos. Portanto, de acordo com a Tabela 4, foi possível constatar que todos os indicadores da variância extraída são superiores aos valores das variâncias compartilhadas. 
Tabela 4 - Teste de Fornell e Larcker para validade discriminante do modelo de mensuração da imagem de loja

\begin{tabular}{lcccccc}
\hline Construtos & $\mathbf{1}$ & $\mathbf{2}$ & $\mathbf{3}$ & $\mathbf{4}$ & $\mathbf{5}$ & $\mathbf{6}$ \\
\hline 1. Atmosfera de Loja & $\mathbf{0 , 5 7 2}$ & & & & & \\
2. Instalação (layout) & 0,061 & $\mathbf{0 , 5 0 7}$ & & & & \\
3. Mercadoria (mix produtos) & 0,120 & 0,110 & $\mathbf{0 , 5 2 1}$ & & & \\
4. Promoção & 0,016 & 0,081 & 0,019 & $\mathbf{0 , 4 5 4}$ & & \\
5. Vendedores & 0,033 & 0,015 & 0,150 & 0,026 & $\mathbf{0 , 5 1 0}$ & \\
6. Serviços & 0,065 & 0,110 & 0,095 & 0,134 & 0,020 & $\mathbf{0 , 5 0 7}$ \\
\hline
\end{tabular}

Fonte: Dados provenientes da pesquisa.

Com base nas análises de componentes principais e a rotação varimax, os seguintes resultados foram obtidos: para as dimensões formadoras da dimensão imagem de loja, apresentou Kaiser-Meyer-Olkin $=0,814$ e $\mathrm{p}<0,000$, com a estrutura rotacionada, a variância total explicada foi de $61,735 \%$. A imagem de loja representa o construto de segunda ordem, e a lealdade dos consumidores é dimensão dependente (Figura 2). Os resultados de ajustamento desse modelo, na Tabela 5, apresentaram valores que estão de acordo com os índices exigidos pela literatura (HAIR Jr. et al., 2010; KLINE, 2011; BAGOZZI; YI, 2012), mas apenas o GFI e TLI apresentaram valores próximos ao nível de fronteira $\left(\chi^{2}=\right.$
899,669; $452 \mathrm{gl} ; \mathrm{p}<0,000 ; \mathrm{x}^{2} / \mathrm{gl}=1,990 ;$ $\mathrm{GFI}=0,873 ; \mathrm{AGFI}=0,852 ; \mathrm{NFI}=0,849$; TLI $=0,910 ;$ CFI $=0,918 ;$ RMSEA $=$ $0,050)$.

Sendo assim, é possível afirmar que o modelo teórico proposto é adequado em função dos ajustes obtidos, que também estão representados na matriz de correlação entre os construtos presentes apresentados na Tabela 5 e na Figura 2. Além do mais, foi possível constatar melhorias dos índices no presente estudo em comparação com o estudo original (Tabela 5). Em decorrência da retirada das dimensões conveniência e institucional, além da inclusão da dimensão lealdade que resultaram em melhorias nos índices do modelo.

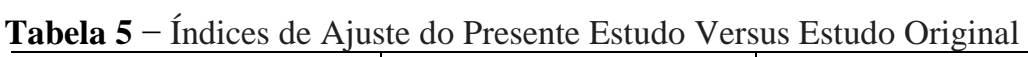

\begin{tabular}{l|c|c|c}
\hline \multicolumn{1}{c|}{ Índice de Ajuste } & Índice de Ajuste & Presente Estudo & $\begin{array}{c}\text { Estudo Original } \\
\text { Preez } \text { et al.(2006) }\end{array}$ \\
\hline$\chi^{2}$ e $g l$ associado & $\chi^{2} / \mathrm{gl}$ & 1,990 & 10,30 \\
Absoluto & GFI & 0,873 & 0,91 \\
Absoluto & AGFI & 0,852 & 0,83 \\
Incremental & NFI & 0,849 & 0,89 \\
Incremental & TLI & 0,910 & - \\
Incremental & CFI & 0,918 & 0,92 \\
Absoluto & RMSEA & 0,050 & 0,14 \\
\hline
\end{tabular}

Fonte: Dados provenientes da pesquisa. 
Com relação ao poder explicativo do modelo teórico proposto, pode-se considerar moderado $\left(\mathrm{R}^{2}=0,238\right)$. $\mathrm{O}$ que indica que a lealdade é explicada por
23,8\% pela imagem da loja, ou seja, existem outras dimensões possíveis que explicam a lealdade (Figura 2).

Figura 2 - Modelo Estrutural Testado

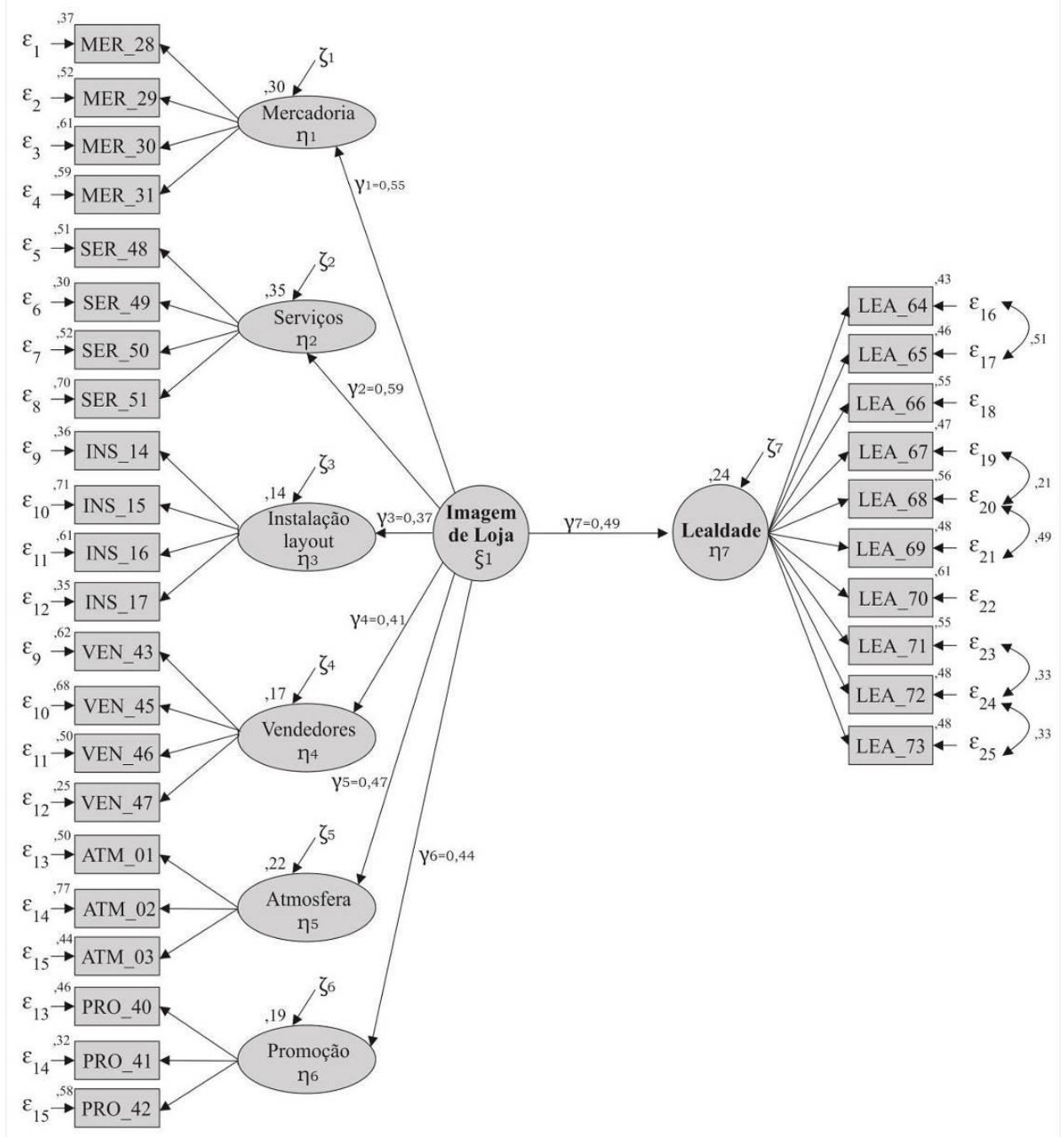

Fonte: Dados provenientes da pesquisa.

$\mathrm{Na}$ Figura 2, com relação a explicação da Imagem de Loja, foi possível constatar que os serviços apresentam uma maior explicação da imagem de 34,9\% ( $K=$ 0,35), seguido pela mercadoria (mix de produtos $) \operatorname{com} 29,7 \% \quad(\kappa=0,30)$, a atmosfera com 21,8\% $(K=0,22)$ em terceiro, promoção com $19 \%(\kappa=0,19)$, vendedores com 16,9\% $(\kappa=0,17)$ e Instalações (Layout) com 14\% $(\kappa=0,14)$ em sexto. Portanto, estes são as dimensões importantes e com alto poder de explicação da Imagem de Loja pela amostra composta pela geração $\mathrm{Y}$. 
Das oito dimensões formadoras da imagem de loja, propostas inicialmente no estudo, Tabela 1, apenas seis construtos (Tabela 6) obtiveram suporte estatístico para serem aceitas e representar a imagem de loja em segunda ordem, são elas: Atmosfera $(\beta=0,2930, p<0,001)$, Instalações $(\beta=0,2140, p=0,001)$, Mercadoria $(\beta=0,3880, p<0,001)$, Promoção $(\beta=0,3030, p=0,001)$, Pessoal de Vendas $(\beta=0,4190, p=0,001)$, Serviços $(\beta=0,5040, p=0,001)$. Também foi confirmada a hipótese $\mathbf{H}_{\mathbf{1}}(\beta=0,2500, p$ $=0,001)$ que trata do impacto da imagem de loja sobre a lealdade.
Por outro lado, os construtos conveniência e institucional não foram rodadas no teste das hipóteses, foram rejeitadas na validade convergente, por apresentarem baixos indicadores de variância extraída e confiabilidade composta. No estudo original de Du Preez, Visser e Janse Van Noordwyk (2006a, b, c), as dimensões Conveniência e Institucional também apresentaram baixa validade convergente, e ficaram com valores de variância extraída em 0,32 e 0,35 respectivamente, chamadas nos resultados do estudo de pobre (Tabela 6).

Tabela 6 - Testes das hipóteses do Modelo do Presente Estudo versus o Estudo Original

\begin{tabular}{|c|c|c|c|c|c|c|}
\hline \multirow{2}{*}{ Hi } & \multirow{2}{*}{ Relacionamentos Causais } & \multicolumn{4}{|c|}{ Presente Estudo } & \multirow{2}{*}{$\begin{array}{c}\text { Estudo } \\
\text { Original } \\
\text { Resultados }\end{array}$} \\
\hline & & $\begin{array}{c}\text { C. R. } \\
(\boldsymbol{\beta})\end{array}$ & S.E. & Sig. & Resultados & \\
\hline & Imagem de Loja $\leftarrow$ Atmosfera de Loja & 0,2930 & 0,0470 & $p=0,000$ & significativo & significativo \\
\hline & Imagem de Loja $\leftarrow$ Conveniência & - & - & - & Não testada* & Pobre \\
\hline & Imagem de Loja $\leftarrow$ Instalações (layout) & 0,2140 & 0,0430 & $p=0,000$ & significativo & significativo \\
\hline & Imagem de Loja $\leftarrow$ Institucional & - & - & - & Não testada* & Pobre \\
\hline & Imagem de Loja $\leftarrow$ Mercadoria (mix) & 0,3880 & 0,0600 & $p=0,000$ & significativo & significativo \\
\hline & Imagem de Loja $\leftarrow$ Promoção & 0,3030 & 0,0560 & $p=0,000$ & significativo & significativo \\
\hline & Imagem de Loja $\leftarrow$ Vendedores & 0,4190 & 0,0770 & $p=0,000$ & significativo & significativo \\
\hline & Imagem de Loja $\leftarrow$ Serviços & 0,5040 & 0,0620 & $p=0,000$ & significativo & significativo \\
\hline $\mathbf{H}_{1}$ & Imagem de Loja $\rightarrow$ Lealdade & 0,2500 & 0,0370 & $p=0,000$ & Suportada & Suportada \\
\hline
\end{tabular}

Fonte: Dados provenientes da pesquisa.

Nota: (*) Os construtos conveniência e institucional não foram testados por apresentarem baixa validade convergente.

Foi verificado o efeito moderador, através da análise de multigrupos com base no teste do escore-z para valores acima de $\pm 1.96, \mathrm{p}<.05$, que indicam o efeito indireto e a influência da variável sobre as dimensões em estudo (SOBEL, 1982). Portanto, foi avaliado quanto o sexo, a frequência de compra e a renda moderam a relação entre as dimensões que compõem a imagem de loja e a lealdade. Em relação ao sexo, observou-se efeito moderador apenas sobre as variáveis mix de produtos e vendedores, ou seja, os homens percebem o mix de produtos e os vendedores de forma diferente comparado às mulheres $\left(\beta_{\text {homem }}=0,26 ; p=0,001 ; \beta_{\text {mulher }}=0,52 ; p\right.$ 
$=0,000$; escore- $\mathrm{z}=2,235)$. Estes achados corroboram com os estudos realizados por Chang, Travaglione e O’Neill (2015), ao qual também percebem diferenças significantes entre os gêneros, em especial a percepção dos consumidores com relação ao gênero dos atendentes. Além do mais, no estudo desenvolvido por Valentine e Powers (2013), foi constatado que para a geração Y, há diferenças de percepção por gênero para as mídias, ao qual o gênero feminino busca por maiores informações, são mais orientadas visualmente, em comparação ao gênero masculino.

Referente à frequência de compra, baixa frequência e alta frequência, apenas a dimensão vendedores apresentou diferença significativa, ou seja, quanto maior ou menor for a frequência de compra pelos consumidores, maior ou menor será a percepção da dimensão vendedores ( $\beta_{\text {baixa }}$ frequência $=0,593 ; p=0,000 ; \beta_{\text {alta frequência }}=$ 0,239; $p=0,034$; escore- $\mathrm{Z}=2,328$ ). E por fim, a moderação através da renda, baixa renda (até $\mathrm{R} \$ 2.000,00, \mathrm{n}=268$ ) e alta renda (acima de $\mathrm{R} \$ 2.000,00, \mathrm{~N}=126$ ), também se constatou que apenas a variável vendedor apresentou diferença significativa $\left(\beta_{\text {baixa renda }}=0,279 ; p=0,003\right.$; $\beta_{\text {alta renda }}=0,727 ; p=0,000 ;$ escore- $\mathrm{Z}=$ $2,800)$.

Serviços foi a dimensão que mais explicou a imagem de loja $(\beta=0,5040 ; p=$
0,000), com impacto direto na lealdade, em relação a imagem de loja. O pessoal de vendas (vendedores) apresentou forte poder explicativo da Imagem de loja $(\beta=$ 0,4190; $p=0,000)$. Em paralelo com a teoria, é possível afirmar que o pessoal de vendas é a linha de frente dos varejistas, é o primeiro contato do cliente com a loja, e são responsáveis por aconselhar e orientar os clientes dentro da loja e em suas compras. Para Hu e Jasper (2006) os vendedores representam a interação social do atendimento. Eles representam a conexão social com a loja, característica percebida pela geração $\mathrm{Y}$, que busca interatividade e interações sociais.

O mix de produtos $(\beta=0,3880 ; p=$ 0,000) também merece destaque, devido à variedade, à qualidade e à marca das mercadorias comercializadas pela loja. Esta dimensão foi influenciada pela renda $\left(\beta_{\text {alta renda }}=0,462\right)$, onde é percebida com maior relevância pelo perfil do mercado pesquisado, neste trabalho. Conclui-se que o mix de produtos é essencial para o varejista de vestuário, logo os gestores devem se concentrar principalmente no que se refere a variedade e qualidade da mercadoria ofertada.

A atmosfera de loja $(\beta=0,2930 ; p$ $=0,000)$, desempenha papel fundamental na percepção do consumidor e afeta sua experiência de compra na loja. 
Concomitante com a teoria, Newman e Patel (2004) relatam que a atmosfera é um dos pontos cruciais e determinantes na escolha da loja, melhora a percepção do consumidor quanto a qualidade dos produtos (RICHARDSON et al. 1996).

A dimensão instalações $(\beta=$ $0,2140 ; p=0,000)$ é percebida como as facilidades para o processo de compras e a infraestrutura para melhorar o conforto do consumidor na hora da compra. São vistas como positivas, porém não com tanta relevância quanto as demais dimensões. Deve-se levar em conta que as instalações podem suavizar a experiência de compra do consumidor: por exemplo, a iluminação transmite a sensação de estar em um ambiente convidativo e pode causar impacto sobre a percepção da loja como um todo. Nesse contexto, a dimensão promoção $(\beta=0,3030 ; p=0,000)$ também aparece como ferramenta importante ao configurar a imagem da loja.

\section{CONSIDERAÇÕES FINAIS}

O objetivo do presente estudo foi examinar a relação entre a imagem de loja e a lealdade dos consumidores da geração Y, bem como a contribuição dos moderadores para tal relação. Constatou-se que a imagem de loja é a soma das percepções que o cliente possui em relação a uma loja. Essa ferramenta permite averiguar quais atributos de imagem de loja são mais significativos para o consumidor e quais, em sua percepção, têm maior influência sobre a configuração da imagem de loja e sobre sua lealdade.

Os resultados deste trabalho apresentam contribuições teóricas que confirmam e fortalecem os estudos iniciais de Du Preez, Visser e Janse Van Noordwyk (2006a, b, c), ao demonstrar que a percepção dos consumidores em relação à imagem de loja desempenha um papel importante na preferência ou escolha da loja por parte dos consumidores. Só é possível atraí-los quando suas expectativas foram atingidas e não houver discrepância na percepção da imagem da loja.

Como contribuições gerenciais, este estudo permite que varejistas do setor de vestuário alinhem suas percepções de configuração da imagem de loja e compreendam o impacto de tal construto sobre a lealdade dos consumidores. Com isso, podem gerir melhor as estratégias ao comunicar suas imagens no mercado, antecipando-se às necessidades de seus clientes de forma a satisfazê-las e gerar posterior lealdade à loja.

Com base nesta pesquisa, é possível compreender que a imagem do varejo de vestuário e sua relação com a lealdade é significativa, haja vista apresentar um 
coeficiente de explicação de $25 \%\left(\mathrm{H}_{1}: \beta=\right.$ 0,2500; $p=0,000)$. Em geral, os resultados evidenciam que outros construtos antecedem a lealdade e que, no caso deste estudo, $25 \%$ de sua explicação pode ser atribuída à imagem que os consumidores possuem das lojas em estudo. Portanto, futuros estudos podem compreender melhor quais dimensões antecedem a lealdade do consumidor, aumentando assim o poder de explicação de futuros modelos propostos.
Dentre as limitações da pesquisa, o método não expõe os entrevistados em um ambiente real para o preenchimento do questionário. Além disso, a loja escolhida pode não ter um envolvimento dos respondentes, o que pode limitar a percepção destes. Estudos futuros podem replicar este para outros tipos de serviço (contextos), com diferentes procedimentos de amostragem, como em supermercados, farmácias, restaurantes etc. 


\section{REFERÊNCIAS}

ABDI - Agência Brasileira de Desenvolvimento Industrial. Estudos setoriais de inovação Indústria têxtil e de vestuário. Projeto: Estudo sobre como as empresas brasileiras nos diferentes setores industriais acumulam conhecimento para realizar inovação tecnológica. FUNDEP/UFMG. $2009 . \quad$ Disponível em: <http://www.sistemamodabrasil.com.br/Upload/Download/industria-textil-edevestuario.pdf>. Acesso em: 11 mar. 2018.

ASSAEL, H. Consumer behavior and marketing action. 4. ed. Boston: PWS-Kent Publishing, 1992.

ANDERSON, E.W.; WEITZ, B. Determinants of continuity in conventional industrial channel dyads. Marketing Science, v.8, n.4, p.310-323, 1989.

BAGOZZI, R.P.; YI, Y. Specification, evaluation, and interpretation of structural equation models. Journal of the Academy of Marketing Science, v.40, n. 1, p.8-34, 2012.

BAKER, J.; GREWAL, D.; PARASURAMAN, A. The influence of store environment on quality inferences and store image, Journal of the Academy of Marketing Science, v. 22, n. 4, p. 328-339, 1994.

BAKER, J.; PARASURAMAN, A.; GREWAL, D.; VOSS, G. B. The influence of multiple store environment cues on perceived merchandise value and patronage intention. Journal of Marketing, v.66, n.4, p.120-144, 2002.

BEARDEN, W. O.; NETEMEYER, R. G.; HAWS, K. L. Handbook of marketing scales: multi-item measures for marketing and consumer behavior research. 3. ed. Thousand Oaks: Sage Publications, 2011.

BENNETT, R.; RUNDLE-THIELE, S. A comparison of attitudinal loyalty measurement approaches. Brand Management, v.9, n. 3, p.193-209, 2002.

BERISTAIN, J.J.; ZONILLA, P. The relationship between store image and store brand equity: A conceptual framework and evidence from hypermarkets. Journal of Retailing and Consumer Services, v.18, n.6, p.562-574, 2011.

BITNER, M.J. Servicescapes: the impact of physical surroundings on customers and employees. Journal of Marketing, v. 56, n. 2, p. 57-71, 1992. 
BLOEMER, J.; RUYTER, K. On the relationship between store image, store satisfaction and store loyalty. European Journal of Marketing, v.32, n. 5/6, p.499-513, 1998.

BOULDING, K. E. The Image: Knowledge in life and society. 6. ed. Ann Harbor: University of Michigan, 1968.

BORGES, A.; BABIN, B.J.; SPIELMANN, N. Gender orientation and retail atmosphere: effects on value perception. International Journal of Retail \& Distribution Management, v. 41, n. 7, p. 496-511, 2013.

BRADY, M.K.; CRONIN, J.J.; BRAND, R.R. Performance-only measurement of service quality: a replication and extension. Journal of Business Research, v.55, n.1, p.17-31, 2002.

CARRILLAT, F.A.; JARIMILLO, F.; MULKI, J.P. Examining the impact of service quality: a meta-analysis of empirical evidence. Journal of Marketing Theory and practice, v.17, n.2, p.95-110, 2009.

CHANG, C.; TU, C. Exploring store image, customer satisfaction and customer loyalty relationship: Evidence from Taiwanese hypermarket industry. The Journal of American Academy of Business, v.7, n.2, p. 197-202, 2005.

CHANG, J.; TRAVAGLIONE, A.; O’NEILL, G. How can gender signal employee qualities in retailing? Journal of Retailing and Consumer Services, v.27, p.24-30, 2015.

COLLINS-DODD, C.; LINDLEY, T. Store brand and retail differentiation: the influence of store image and store brand attitude on own store brand perception. Journal of Retailing and Consumer Services, v.10, n.6, p.345-352, 2003.

CRONIN, J.J.; TAYLOR, S.A. Measuring service quality: a re-examination and extension. Journal of Marketing, v.56, n.3, p.55-68, 1992.

DE TONI, D.; LARENTIS, F.; MATTIA, A. A.; GILIOLI, R. M.; MILAN, G. S. Consumo Consciente e seus Impactos sobre o Valor Percebido e Lealdade em Produtos Ecologicamente Corretos: Proposição e Teste de um Modelo Teórico. Revista Gestão Organizacional, v.6, n.2, p.4-20, 2013.

DARDEN, W.R.; BABIN, B.J. Exploring the concept of affective quality: expanding the concept of retail personality. Journal of Business Research, v. 29, n. 2, p. 101-110, 1994. 
DE WULF, K.; ODEKERKEN-SCHRÖDER, G.; LACOBUCCI, D. Investments in consumer relationships: a cross-country and cross-industry exploration. Journal of Marketing, v. 65, p.33-50, 2001.

DJAMASBI, S.; SIEGEL, M.; TULLIS, T. Generation Y, web design, and eye tracking. International Journal of Human-Computer Studies, v. 68, n. 5, p. 307-323, 2010.

DO VALE, R.C.; MATOS, P.V.; CAIADO, J. The impact of private labels on consumer store loyalty: Na integrative perspective. Journal of Retailing and Consumer Services, v. 28, p. 179-188, 2016.

DU FRENE, D. D; ENGELLAND, B. T.; LEHMAN E PEARSON C. M, R. A. Changes in consumer attitudes resulting from participation in a permission e-mail campaign. Journal of Advertising Current Issues and Research, v.27, n.1, p.65-77, 2005.

DU PREEZ, R.; VISSER E. M.; JANSE VAN NOORDWYK, H. S. Store Image: Toward a Conceptual Model - Part 1. SA Journal of Industrial Psychology, v.34, n.2, p.50-58, 2006a.

DU PREEZ, R.; VISSER E. M.; JANSE VAN NOORDWYK, H. S. Store Image: Scale Development - Part 2. SA Journal of Industrial Psychology, v. 34, n. 2, p.59-66, 2006 b.

DU PREEZ, R.; VISSER E. M.; JANSE VAN NOORDWYK, H. S. Store Image: Toward a Conceptual Model - Part 3. SA Journal of Industrial Psychology, v.34, n.2, p.69-78, 2006c.

ERDEM, O.; OUMLIL, A. B.; TUNCALP, S. Consumer values and the importance of store attributes. International Journal of Retailing and Distribution Management, v.27, n.4, p.137-144, 1999.

ESPARTEL, L. B. O que é lealdade de clientes e quais os seus benefícios às empresas? In: Administração mercadológica: teoria e pesquisas. In: MILAN, G. S.; BRANCHI, N. V. L. (org.). Caxias do Sul: EDUCS, 2004, cap. 10, 223-243.

ESPARTEL, L. B. Um estudo longitudinal da lealdade do cliente e de seus antecedentes. 2005. 216 p. Tese (Doutorado em Administração). Escola de Administração, UFRGS, Porto Alegre, 2005.

FINK, A. How to conduct surveys: a step-by-step guide. 5. ed. Thousand Oaks: Sage Publications, 2013. 
FORNELL, C.R. A national customer satisfaction barometer: the Swedish experience. Journal of Marketing, v.56, n.1, p.6-21, 1992.

FORNELL, C.R.; LARCKER, D.F. Evaluating structural equation models with unobservable variables and measurement error. Journal of Marketing Research, v.18, n.1, p.39-50, 1981.

FOWLER JR., F. J. Survey research methods. 4. ed. Thousand Oaks: Sage Publications, 2009.

HAIR Jr., J. F. Multivariate data analysis. 7. ed. Upper Saddle River: Prentice Hall, 2010.

HU, H.; JASPER, C.R. Social cues in the store environment and their impact on store image. International Journal of Retail \& Distribution management, v.34, n.1, p.25-48, 2006.

HUDDLESTON, P.; FORD, I.; MAHONEY, M. The relationship between importance of retail store attributes and lifestyle of mature female Consumers. Journal of Consumer Studies and Home Economics, v. 14, n.1, p.71-85, 1990.

HYLlEGARD, K.; ECKMAN, M.; DESCALS, A. M.; BORJA, M. A. G. Spanish Consumers' perception of US specialty apparel retailers' products and services. Journal of Consumer Behaviour, v.4, n.5, p.345-362, 2005.

IEMI (Instituto de Estudos e Marketing Industrial). Brasil têxtil: Relatório setorial da cadeia têxtil brasileira. Anual. v. 14, n. 14, ago. 2014, ex. 1. São Paulo, 2014.

IEMI (Instituto de Estudos e Marketing Industrial). Mercado de Vestuário e Têxtil: Desempenho Indústria e Varejo. Mar/Jun, 2016.

IEMI (Instituto de Estudos e Marketing Industrial). Indicadores: Volume de vendas do varejo de vestuário avançou 13,8\% em novembro. Fev. 2018. Disponível em: < http://www.iemi.com.br/indicadores-volume-de-vendas-do-varejo-de-vestuario-avancou-138em-novembro/>. Acesso em: 11 mar. 2018.

JAMES, D.L.; DURAND, R.M.; DREVES, R.A. The use of a multi-attributes attitudes model in a store image study. Journal of Retailing, v.52, n.2, p.23-32, 1976.

JANSE VAN NOORDWYK, H.S. The development of a scale for the measurement of the perceived importance of the dimensions of apparel store image, 2008. Tese de Doutorado, UNIVERSIDADE DE STELLENBOSCH, Africa do Sul, 2008. 
KENT, T. Management and perspectives on retail branding design. International Journal of Retail \& Distribution Management, v.31, n.3, p.131-142, 2003.

KIM, J. O.; JIN, B. Korean consumer's patronage of discount stores: domestic versus multinational discount store shoppers profiles. Journal of Consumer Marketing, v.18, n.3, p.236-255, 2001.

KINNEAR, T. C.; TAYLOR, J. R. Marketing research: An applied approach. 5. ed. New York: McGraw-Hill, 1996.

KLINE, R. B. Principles and Practice of Structural Equation Modeling. New York: The Guilford Press, 2011.

KUMAR, V.; SHAH, D. Building and Sustaining Profitable Customer Loyalty for the 21st Century. Journal of Retailing, v.80, n.4, p.317-330, 2004.

LEWIS, B. R.; HAWKSLEY, A. W. Gaining a competitive advantage in fashion retailing. International Journal of Retail and Distribution Marketing, v.18, n.4, p.21-32, 1990.

LIN, L-Z.; YEH, H-R. A means-end chain of fuzzy conceptualization to elicit consumer perception in store image. International Journal of Hospitality Management, v.33, n.1, p.376-388, 2013.

MALHOTRA, N. K.; BIRKS, D.; WILLS, P. Marketing research: applied approach. 4. ed. New York: Pearson, 2012.

MARTINEAU, P. The personality of the retail store. Harvard Business Review, v.36, n.1, p.47-55, 1958.

MARKWICK, N.; FILL, C. Towards a framework for managing corporate identity. Europe Journal of Marketing, v.31, n.5, p.396-409, 1997.

MAY, E. G. Practical applications of recent retail image research. Journal of Retailing, v.50, n.4, p.15-20, 1974.

NETEMEYER, R. G.; BEARDEN, W. O.; SHARMA, S. Scaling procedures: issues and applications. Thousand Oaks: Sage Publications, 2003. 
NEWMAN, J.; PATEL, D. The marketing directions of two fashion retailers. European Journal of Marketing, v.38, n.7, p.770-789, 2004.

NORTH, E. J.; DE VOS, R. B.; KOTZE, T. The importance of apparel product attributes for the females buyers. Journal of Family Ecology and Consumer Science, v.31, p.41-51, 2003.

OLIVER, R. L. Whence Consumer Loyalty? Journal of Marketing, v. 63, Special Issue, p. 33-44, 1999.

ORTH, U. R.; GREEN, M. T. Consumer loyalty to family versus non-family business: The roles of store image, trust and satisfaction. Journal of Retailing and Consumer Services, v. 16, n.4, p.248-259, 2009.

OSMAN, M. Z. The Conceptual model of retail image influences on loyalty patronage behavior. International Review of Retail, Distribution and Consumer Research, v.3, n.2, p.133-148, 1993.

PIRIS, Y.; GUIBERT, N. Effects of intuitive judgments on consumer assortment evaluations. Journal of Consumer Marketing, v.32, n.3, p.137-144, 2015.

PORTER, S.; CLAYCOMB, C. The influence of brand recognition on retail store image. Journal of Product and Brand Management, v.6, n.6, p.373-387, 1997.

RATNATUNGA, J.; EWING, J. M. The brand value of integrated marketing capability communication (IMC). Journal of Advertising, v.34, n.4, p.25-40, 2005.

REMLER, D. K.; VAN RYZIN, G. G. Research methods in practice: Strategies for description and causation. Thousand Oaks: Sage Publications, 2011.

RICHARDSON, P.; JAIN, A. K.; DICK, A. The influence of aesthetics on store evaluation of private label brands. Journal of Product and Brand Management, v.5, n.1, p.19-28, 1996.

SEN, S.; BLOCK, L.G.; CHANDRAN, S. Window displays and consumer shopping Decisions. Journal of Retailing and Consumer Services, v.9, n.5, p.277-291, 2002.

SIMONSON, I. Determinants of customers' responses to customized offers: conceptual framework and research propositions. Journal of Marketing, v.69, n.1, p.32-45, 2005. 
SIRGY, M.J.; SAMLI, A.C. A path analytic model of store loyalty involving self-concept, store image, geographic loyalty, and socioeconomic status. Journal of the Academy of Marketing Science, v.13, n.3, p.265-291, 1985.

SIROHI, N.; McLAUGHLIN, E.W.; WITTINK, D.R. A model of consumer perceptions and store loyalty intentions for a supermarket retailer. Journal of Retailing, v.74, n.2, p.223-245, 1998.

SOBEL, M. Asymptotic intervals for indirect effects in structural equations models. In: Leinhart, S. (Ed.). Sociological methodology. San Francisco: Jossey-Bass, 1982, p.290-312.

STERN, B.; ZINKHAN, G.; JAJU, A. A marketing images: construct definition, measurement issue, and theory development. Marketing Theory, v.1, n.2, p.201-224, 2001.

SZYMANSKI, D.M.; HENARD, D.H. Customer satisfaction: a meta-analysis of the empirical evidence. Journal of the academy of marketing science, v.29, n.1, p.16-35, 2001.

TAPSCOTT, D. Geração digital: a crescente e irreversível ascensão da geração Net. São Paulo: Makron Books, 1999.

TAPSCOTT, D.; WILLIAMS, A. Wikinomics: como a colaboração em massa pode mudar o seu negócio. Rio de Janeiro: Nova Fronteira, 2007.

TAYLOR, S.L.; CONSENZA, R.M. Profiling later aged female teens: mall shopping behavior and clothing choice, Journal of Consumer Marketing, v.19, n.5, p.393-408, 2002.

TELLER, C.; KOTZAB, H.; GRANT, D.B. The consumer direct services revolution in grocery retailing: An exploratory investigation. Managing Service Quality, v.16, n.1, p.7896, 2006.

TERBLANCHÉ, N. S.; BOSHOFF, C. The generic instrument to measure customer satisfaction with the controllable elements in-store shopping experience. South African Journal of Business Management, v.3, n.3, p.1-15, 2006.

THANG, D. C. L.; TAN, B. L. Linking consumer perception to preference of retail stress: an empirical assessment of the multi-attributes of store image. Journal of Retailing Consumer Services, v.10, n.7, p.193-201, 2003. 
VALENTINE, D.B.; POWERS, T.L. Generation Y values and lifestyle segments. Journal of Consumer Marketing, v.30, n.7, p.597-606, 2013.

VARLEY, R. Store Image as the key differentiator. European Retail Digest, v.46, p.18-21, Summer 2005.

VISSER, E. M.; DU PREEZ, R.; JANSE VAN NOORDWYK, H. S. Importance of apparel store image attributes: Perceptions of female consumers. Marketing Dynamics, v.32, n.3, p.49-62, 2006.

WANG, L. C.; CHANG, L. H.; WYSONG, S. An empirical investigation of the influence of optimum stimulation levels in retailing. International Journal of Retail \& Distribution Management, v.40, n.1, p.6-20, 2012.

WATERS, J. Young, with tons of purchasing power. Market Watch, The Wall Street Journal Digital Network, Chicago, 2006.

YOO, B.; DONTHU, N. Developing and validating multidimensional consumer-based brand equity scale. Journal of Business Research, v.52, n.1, p.1-14, 2001.

YOO, B.; DONTHU, N.; LEE, S. An examination of selected marketing mix elements and brand equity. Journal of the Academy of Marketing Science, v.28, n.2, p.195-211, 2000.

YOON, S.-J.; SIMONSON, I. Choice set configuration as a determinant of preference attribution and strength. Journal of Consumer Research, v.35, n.2, p.324-336, 2008.

ZEITHAML, V.A.; BERRY, I.I.; PARASURAMAN, A. The behavioral consequences of service quality. Journal of marketing, v.60, n.2, p.31-46, 1996. 